\title{
Anti-oxidant and Anti-inflammatory Activities of Manilkara zapota (Sapodilla) In vitro and Efficiency in Healthy Elderly Persons
}

\author{
Jirakrit Leelarungrayub*1, Thanyaluck Sriboonreung ${ }^{1}$, Yothin Pothasak ${ }^{1}$, Jynwara Kaju ${ }^{1}$ \\ and Rungthip Puntumetakul ${ }^{2}$ \\ ${ }^{1}$ Department of Physical Therapy, Department of Physical Therapy, Faculty of Associated Medical Sciences, Chiang Mai University, Chiang \\ Mai, Thailand \\ ${ }^{2}$ Research Center in Back, Neck, Other Joint Pain and Human Performance (BNOJPH), Khon Kaen University, Khon Kaen, Thailand \\ *Corresponding author: Jirakrit Leelarungrayub, Department of Physical Therapy, Faculty of Associated Medical Sciences, Chiang \\ Mai 50200, Thailand
}

\section{ARTICLE INFO}

Received: 㹃 February 18, 2019

Published: 蔧 February 28, 2019

Citation: Jirakrit Leelarungrayub*, Thanyaluck Sriboonreung, Yothin Pothasak, Jynwara Kaju, Rungthip Puntumetakul. Anti-oxidant and Antiinflammatory Activities of Manilkara zapota (Sapodilla) in vitro and Efficiency in Healthy Elderly Persons. Biomed J Sci \& Tech Res 15(2)-2019. BJSTR. MS.ID.002684.

Keywords: Sapodilla; Antioxidants; Anti-inflammation; Cytokines; Elderly

\begin{abstract}
Sapodilla is one of many fruits that has been consumed in all people in Thailand, especially in the elderly. The aim of this preliminary was to evaluate the antioxidant compounds, radical scavenging and anti-inflammatory activities of ripe sapodilla extracts, and the effects of their consumption on antioxidants, vitamins, lipid profiles, cytokines, and walking distance in healthy elderly volunteers. Vitamin $\mathrm{A}, \mathrm{E}$ and $\mathrm{C}$, total phenolics, the activity of scavenging Superoxide $\left(\mathrm{O}_{2}{ }^{\circ}\right)$, Hydroxyl $\left(\mathrm{OH}^{\circ}\right)$, Hydrogen Peroxide $\left(\mathrm{H}_{2} \mathrm{O}_{2}\right)$ and Nitric Oxide (NO), and inhibition of Tumor Necrosis Factor-Alpha (TNF- $\alpha$ ) were identified in vitro. Whereas in elderly subjects, Total Antioxidant Capacity (TAC), Glutathione (GSH), Malondialdehyde (MDA), Protein Hydroperoxide (PrOOH), Nitric Oxide (NO), vitamins, lipid profiles (triglyceride, cholesterol, high-density lipoprotein-cholesterol; HDL-C, lowdensity lipoprotein; LDL), glucose, TNF- $\alpha$, interleukin (IL-23 and IL-2), and 6- Minute Walking Distance (6MWD) were evaluated before and after 4-week consumption of $100 \mathrm{~g}$ of fresh sapodilla fruit twice daily.

Results specific to in vitro data showed that sapodilla extract contained vitamin $\mathrm{C}$ and $\mathrm{A}$, total phenolics, scavenged $\mathrm{OH}^{\circ}, \mathrm{O}_{2}{ }^{\circ-}$, NO, and $\mathrm{H}_{2} \mathrm{O}_{2}$, and inhibited TNF- $\alpha$ in a dose-dependent manner. The results in elderly individuals showed a significant increase of TAC, and vitamin $\mathrm{C}$ and $\mathrm{A}$, while the NO level decreased. A significant decrease in cholesterol and increase in glucose with no significant change in all cytokines, were noted after consumption. Finally, the 6MWD improved significantly. This preliminary study demonstrates that ripe sapodilla fruit shows antioxidant and anti-inflammatory activities and benefits for health status among elderly persons.
\end{abstract}

\section{Introduction}

In recent years, fruits are being explored for their provision of health enhancement for those of all ages, especially those with impaired-immunity as the elderly. The elderly people in Thailand is being increased [1] and those are at high risk of illness and disease as lung cancer, diabetes or hypertension [2,3]. In addition, the chronic diseases during aging strongly relate to imbalance of oxidative stress status [4] such as low Glutathione (GSH) or multi-vitamins and high lipid or protein oxidation [4,5]. Although, oxidation of Low-Density Lipoprotein (LDL) and cholesterol related to hypertension [6], it indicates beneficial for cell survival in case of Parkinson's disease [7]. Whereas, a chronic period of oxidative stress involves the muscle strength, endurance and function capacity $[8,9]$. Moreover, alternation of HDL composition affects to endopeptidase dysfunction [10], cholesterol efflux and inhibit oxidation of LDL $[11,12]$ that also associated with hypertension or atherosclerosis [13]. Furthermore, impaired immune response and high inflammatory status are found commonly in the elderly during the normal aging process [14]. Chronic inflammation can be evaluated from various pro-inflammatory cytokines $[15,16]$ such as Interleukin-6 (IL-6), Interleukin-1 (IL-1), C-Reactive Protein (CRP), and Tumor Necrosis Factor-Alpha (TNF- $\alpha)[17,18]$. 
The immune system, T lymphocytes, and B cells are importance cells that becomes impair by oxidants during the aging process [19]. Especially, cytokines as Interleukins (IL) secreted by T-lymphocytes [20] and IL-23 or IL-12 from the Dendritic Cells (DC) and macrophages releasing $[21,22]$ indicate the inflammatory condition. Previous data reported that increased IL-23 relates to autoimmune diseases and inflammatory responses [23] as same as the releasing of TNF- $\alpha$ can stimulate the free radicals in mitochondria and result in decreased Nitric Oxide (NO) bioavailability [24]. Therefore, chronic oxidative stress and inflammation is co-distributed within the elderly people that reduce muscle strength, endurance, and functional capacity $[8,9]$.

At present, an improvement the elderly health is being encouraged worldwide by exercise or the intake of extra-nutrients or supplementation. Functional foods and fruit such as grape peel, milk, red and green peppers, garlic, onions, or vegetables [25] that have both antioxidant and immune modulatory function are very challenged because of plenty of various antioxidants (vitamin A, E, and C) [26]. For instance; Vitamin $C$ has the potential to enhance the immune system of elderly individuals by increasing the proliferative response of T lymphocytes [27,28]. Vitamin E in tomatoes [29], and orange juice, which contains flavones that had proven beneficial effects on the cognitive skill of healthy elderly persons [30].

In Thailand, there have many fruits that are available for allyear consumption such as pomelo, banana, grape, papaya, and pineapple, as well as seasonal fruits as durian, rambutan, or custard apple. These fruits containing various multi-vitamins and polyphenolic compounds have antioxidant activity and benefits for human health [31]. One of all seasonal fruits, the efficiency of Star fruit (Averrhoa carambola L.) supplementation in elderly persons that had been studied with was found to have the antioxidant activity and active compounds as L-ascorbic acid (vit C), retinoic acid (vit A), including improved on HDL and reduced on LDL [32]. Moreover, it reduced the inflammatory condition by inhibited the TNF- $\alpha$, IL-23 and Nitric Oxide (NO) [33].

Sapodilla is also one of many fruits in Thailand, which has classified as Achras Zapota Less, or the scientific name of Manilkara zapota Less that can be found in other countries. This fruit has a sweet taste when ripe and small size of $4-8 \mathrm{~cm}$ in diameter. It is ellipsoid or round and contains two to five seeds. The color of its flesh ranges from a pale yellow to an earthy brown with a grainy textured skin, and it is consumed mostly around harvest time during January in Thailand. The nutritional composition and scientific evidence have not been reported or studied much. Information on national nutrient for the standard reference of ripe sapodilla in the United States Database from Department of Agriculture in 2015, showed that $100 \mathrm{~g}$ of sapodilla comprises carbohydrates (19.96 g), vitamin C (14.7 mg), and vitamin A (3 $\mu \mathrm{g}$ ) with $83 \mathrm{Kcal}$ of total energy [34]. Other health benefits of sapodilla have been reported; for example, its leaves can treat coughs and colds, and it possesses diuretic, antidiarrheal, antibiotic, antihyperglycemic, and hypocholesterol properties [35].

In addition, Manilkara zapota leaf juice was able to reduce the levels of glycemia, insulin, leptin, cholesterol, and triglycerides in wistar rats. Moreover, previous data indicated the antioxidant function of Manilkara zapota from polyphenolics, especially gallocatechin or catechin [36], and also neo-bioactive polyphenols with methyl 4-0-galloylchlorogenate and 4-0-galloylchlorogenic acid in methanolic extracted sapodilla [37]. Therefore, sapodilla is a very interesting fruit, but there has been no evidence of whether its supplement can prove beneficial to elderly individuals, especially regarding oxidative stress, inflammation, lipid profiles and capacity of physical function. Therefore, this preliminary study was designed to evaluate its activities in vitro and the effectiveness of healthy elderly persons from regular consumption.

\section{Materials and Methods \\ Experimental Design}

Ripe sapodilla fruit was purchased weekly from the same local farmer in Chiang Mai province. Ripe fruit was selected approximately 3 weeks post-harvest because of its sweet and nonacerbic taste at that stage.

This study was divided into two steps;

A. To identify active compounds and antioxidant activity, as well as anti-inflammatory and immune response to ripe sapodilla extracts in vitro, and

B. To evaluate the effect on antioxidant status, inflammation, lipid profiles and physical function in healthy elderly person individuals after consuming 3-4 ripe sapodilla samples (100 g) twice daily for 4 weeks.

This study determined multi-vitamins in vitro such as L-ascorbic acid (Vit C), retinoic acid (Vit A), alpha-tocopherol (Vit E), and total phenolics. Superoxide Radicals $\left(\mathrm{O}_{2}{ }^{\circ}\right)$, Hydroxyl Radicals $\left(\mathrm{OH}^{\circ}\right)$, Hydrogen Peroxide $\left(\mathrm{H}_{2} \mathrm{O}_{2}\right)$ and Nitric Oxide (NO) were evaluated for scavenging. Moreover, the activity of sapodilla extract in inflammatory TNF- $\alpha$ cytokine release from the Lipopolysaccharide (LPS)-activated Peripheral Blood Mononuclear Cell (PBMC) was evaluated. A 2-week control period for healthy elderly persons was followed by a 4-week duration, in which they consumed ripe sapodilla (100 g) after breakfast and dinner. All parameters;

A. Antioxidant status such as Total Antioxidant Capacity (TAC), Glutathione (GSH), protein hydroperoxide (PrOOH), MDA, NO, Vit A, Vit E, Vit C, and lipid profiles (triglyceride, cholesterol, HDL-C, LDL), as well as glucose level,

B. Inflammatory cytokines, such as TNF- $\alpha$, interleukin-23 (IL-23) and IL-2, and

C. A 6-minute walking distance (6MWD), which measured the physical capacity of the elderly, were evaluated three times (at week 0 and 2 for the controls and week 6, after 4 weeks of sapodilla consumption).

\section{Recruitment of Elderly Participants}

This research protocol was approved by the Human Ethics Committee at the Faculty of Associated Medical Sciences, Chiang Mai University, Thailand, and performed in accordance with the Helsinki Declaration (2001) (Ethical Approval Number 027E/52). The sample size was calculated by the G*Power (3.1.9.2) program with an effect size $=0.92$, alpha error $=0.05$, and power $=0.95$ 
followed the previous study [32], the minimum of 24 healthy elderly subjects were statistically included. Whereas, there had 38 elderly people who stayed at Piyaman Elderly Health Care Center in Chiang Mai province, Thailand. Therefore, all 38 elderly peoples were invited to this study. However, the inclusive criteria stated that all participants must be healthy and free from any acute or chronic illness, non-smoking, especially diabetes and hypertension. All of the elderly participants were capable of performing their basic daily activities independently and lived on their own. Subjects were excluded, if they had any previous illness such as pulmonary disease; asthma, Chronic Obstructive Pulmonary Disease (COPD), and heart disease, or musculoskeletal illness such as osteoarthritis, gout, moderate-to-severe scoliosis, or any degenerative joint diseases, as indicated from hospital reports.

Before starting the protocol, their health status was evaluated clinically from a Complete Blood Count (CBC) and liver function test, and examined physically by a physician in the AMS Clinical Service Center at the Faculty of Associated Medical Sciences, Chiang Mai University, Thailand. From the total of 38 elderly people (25 men and 13 women) who volunteered in this study after provided written consent, the preliminary of $\mathrm{CBC}$ screening showed abnormal results in 6 subjects, and 5 elders were excluded because of forgot supplement more than five days during the experiment (20\%). Finally, the remaining 27 individuals completed the study. During the 6 weeks of this study, the basic daily activities, behavioral patterns, including avoidance of taking extra-supplementary vitamins of all volunteers were controlled.

\section{In Vitro Experiment}

Multi-Vitamins and Total Phenolic Evaluation: Ripe sapodilla extract was elaborately prepared on the dry freezing technique after fine homogenizing with a motor blender and separating all fibers. Vit A and Vit E were identified in sapodilla extract by following the Talwar's protocol [38], whereas Vit C determination followed the Furusawa's protocol [39]. Lipid-soluble Vit A and E were extracted with hexane (1:1/w:v) and chloroform (1:1/v:v). All of the vitamins were identified by the High-Performance Liquid Chromatography (HPLC) system, which comprised a C-18 reverse-phase column (250x4.6x5.0 mm, Phenomenex) with different mobile solutions; and a mixture of methanol-acetonitrite and tetrahydrofuran (75:20:5/v:v:v) for Vit A and Vit E identification, whereas 2\% acetic acid solution in water was used for $\mathrm{Vit} C$ analysis. The flow rate was $1.0 \mathrm{~mL} / \mathrm{min}$. Peaks of Vit A, E, and C were identified at 325, 294, and $254 \mathrm{~nm}$, respectively, by comparing with the peaks of each standard vitamin (Sigma, USA)

Moreover, total phenolics were evaluated by following the protocol of Zheng and Wang with Folin-Ciocalteu reagent [40]. Aliquots $(250 \mu \mathrm{L})$ of extract $(10 \mathrm{mg})$ were mixed with $1 \mathrm{~mL}$ of FolinCiocalteu reagent and $1 \mathrm{~mL}$ of $\mathrm{Na}_{2} \mathrm{CO}_{3}(10 \%$; w/v). After incubation for $1.5 \mathrm{~h}$ at $30^{\circ} \mathrm{C}$, the absorbance was measured at $765 \mathrm{~nm}$. Total phenolics were presented by comparison to standard gallic acid (Sigma, USA).

Anti-Radical Protocols: The superoxide $\left(\mathrm{O}_{2}{ }^{\circ}\right)$ scavenging assay was performed by following the previous protocol of Hazra and Biswas [41]. The mixed solution of $760 \mu \mathrm{L}$ of hypoxanthine
(1.1 $\mathrm{mM})$ and $100 \mu \mathrm{L}$ of Nitroblue Tetrazoium (NBT) $(300 \mu \mathrm{M})$ was mixed with $100 \mathrm{~mL}$ of sapodilla extracts $(25,50$, or $100 \mathrm{mg} /$ $\mathrm{mL})$, with $40 \mu \mathrm{L}$ of xanthine oxidase $(1.67 \mathrm{U} / \mathrm{mL})$ added. The reduction of absorbance was read at $560 \mathrm{~nm}$ every 15 seconds with a spectrophotometer, and the results showed an extract concentration (mg) of $50 \%$ or IC50 for inhibition.

The Hydroxyl Radical $\left(\mathrm{OH}^{\circ}\right)$ scavenging assay followed the protocol of Wang and co-worker [42]. One hundred $\mu \mathrm{L}$ of sapodilla extract $(25,50$, or $100 \mathrm{mg} / \mathrm{mL})$ was mixed in a solution of $200 \mu \mathrm{L}$ of deoxyribose (15 mM), $200 \mu \mathrm{L}$ of $\mathrm{K}_{2} \mathrm{HPO}_{4}$-KHO (100 mM), $200 \mu \mathrm{L}$ of $\mathrm{FeCl}_{3}(500 \mu \mathrm{M}), 100 \mu \mathrm{L}$ of Ethylenediaminetetracetic Acid (EDTA) (1 $\mathrm{mM}$ ), and $100 \mu \mathrm{L}$ of $\mathrm{H} 2 \mathrm{O} 2(10 \mathrm{mM})$, before adding $100 \mu \mathrm{L}$ of ascorbic acid solution ( $1 \mathrm{mM})$. After incubating at room temperature for $1 \mathrm{hr}$, $1 \mathrm{~mL}$ of 2-Thiobarbituric (TBA) (1\%) and $1 \mathrm{~mL}$ of Trichloroacetic Acid (TCA) (2.8\%) were mixed. After boiling at $80^{\circ} \mathrm{C}$ for $20 \mathrm{~min}$, a pink color complex was produced and the absorbance was read at $532 \mathrm{~nm}$ with a spectrophotometer. Results showed an extract concentration (mg) of 50\% or IC50 for inhibition.

Hydrogen peroxide $\left(\mathrm{H}_{2} \mathrm{O}_{2}\right)$ scavenging was tested by following the protocol of Jha et al. [43]. Totally $2.3 \mathrm{~mL}$ of phosphate buffer (pH 6.0) containing various sapodilla extracts $(25,50$, or $100 \mathrm{mg} /$ $\mathrm{mL}$ ) was prepared before adding $50 \mu \mathrm{L}$ of $\mathrm{H}_{2} \mathrm{O}_{2}(0.1 \%), 100 \mu \mathrm{L}$ of horseradish peroxidase $(10 \mathrm{U} / \mathrm{mL})$, and then $600 \mu \mathrm{L}$ of 2,2 '-azinobis (3-ethylbenzothiazoline-6-sulphonic acid) (ABTS) (0.1\%), respectively. After incubating at room temperature for $15 \mathrm{~min}$, a blue color was read at $415 \mathrm{~nm}$ with a spectrophotometer. Results showed an extract concentration (mg) of $50 \%$ or IC50 for inhibition.

The Nitric Oxide (NO) scavenging assay was carried out by following the protocol of Sreejayan and Rao [44]. 2.3mL of NO precursor, produced as sodium nitroprusside ( $5 \mathrm{mM})$, was mixed with $100 \mu \mathrm{L}$ of various sapodilla extracts $(25,50$, or $100 \mathrm{mg} / \mathrm{mL})$. After incubating for $30 \mathrm{~min}, 500 \mu \mathrm{L}$ of $0.1 \% \mathrm{~N}-1$-Napthylethylene Dihydrochloride (NED) and $500 \mu \mathrm{L}$ of Sulfanilamide (1\%) were added. Then, a pink color was read at $546 \mathrm{~nm}$ with a spectrophotometer after $10 \mathrm{~min}$ incubation in the dark. Results showed an extract concentration (mg) of $50 \%$ or IC50 for inhibition.

\section{Anti-Inflammatory Response Protocol}

This protocol was performed by following that of Shalini et al. [45]. Peripheral Blood Mononuclear Cells (PBMC) were selected after being separated by Ficoll-paque solution (GE Health care, UK) and washed three times in Phosphate-Buffered Saline (PBS) solution. After the PBMC had been separated and treated in the Roswell Park Memorial Institute (RPMI)-1640 media (10\% heatinactivated fetal bovine serum, 1\% l-glutamine, 1\% HEPES, and $0.5 \%$ penicillin-streptomycin) for 3 days until the106 cells were present in each well. Fifty $\mu \mathrm{L}$ of Lipopolysaccharide (LPS) $(1 \mu \mathrm{g} /$ $\mathrm{mL}$ ) (Sigma-Aldrich, UK) activated the inflammatory cytokine, with a $20 \mu \mathrm{L}$ mixture of sapodilla extracts at various concentrations $(10,20$, or $40 \mathrm{mg} / \mathrm{mL})$ and hydrocortisone (50 ng/mL). After culturing in $95 \%$ humidified air containing $5 \% \mathrm{CO} 2\left(37^{\circ} \mathrm{C}\right)$ for $24 \mathrm{hr}$, the supernatants were collected after centrifugation, and tumor-necrosis factor-alpha (TNF- $\alpha$ ) was determined by specific Quantikine ELISA-kit, R\&D systems (USA). 


\section{Protocol for Healthy Elderly Subjects}

$25 \mathrm{~mL}$ of blood was taken from the anterior cubital vein of the subjects by a medical technologist during the three protocol periods and put into sterile heparin-containing tubes. Firstly, $10 \mathrm{~mL}$ of the blood was taken to assay the Complete Blood Count (CBC) and liver function, as well as lipid profiles such as triglyceride, cholesterol, HDL-C, and LDL by a fully automated Olympus AU400 Analyzer (Olympus Diagnostics GmbH, Germany) at the AMS Clinical Service Center, Faculty of Associated Medical Sciences, Chiang Mai University, Thailand. A second $10 \mathrm{~mL}$ of blood was separated in order to evaluate all oxidative stress markers (TAC, GSH, MDA, PrOOH, and NO) and multi-vitamins (Vitamin A, Vitamin E, and Vitamin C). Finally, $5 \mathrm{~mL}$ of residual blood was separated in order to evaluate the cytokine markers; TNF- $\alpha$, IL-23, and IL-2 using the Quantikine ELISA-kit, R\&D systems (USA). After that, the 6MWD was assessed outdoors.

\section{Protocol for Oxidative Stress}

The TAC of fresh plasma was evaluated by following the ABTS decolorization method [46]. The ABTS radicals were produced by co-incubating ABTS (14 mmol/L) and potassium persulfate (14 mmol/L) overnight in a cool room. $10 \mu \mathrm{L}$ of fresh plasma was added gently into a cuvette containing $990 \mu \mathrm{L}$ of ABTS radicals, which showed $0.70 \pm 0.02$ absorbance, and was read quickly within 3 minutes by spectrophotometry at $734 \mathrm{~nm}$. TAC was expressed by $\Delta \mathrm{A} / \mathrm{min}$, and compared with standard Trolox (Sigma), as mmol of standard Trolox per liter of plasma (mmol Trolox/L).

GSH in whole blood was determined using the 5, 5'-dithio-bis (2-nitrobenzoic acid) (DTNB) protocol [32]. Whole blood (400 $\mu \mathrm{L})$ was precipitated with a precipitating solution $(1.0 \mathrm{~mL})$ before separating the $500 \mu \mathrm{L}$ of supernatant for mixing with $500 \mu \mathrm{L}$ of DTNB and $500 \mu \mathrm{L}$ of phosphate buffer ( $\mathrm{pH}$ 8.0) solution. After incubating at room temperature for $5 \mathrm{~min}$, a clear yellow supernatant solution was read by spectrophotometry at $412 \mathrm{~nm}$. The GSH concentration was calculated by comparing with the absorbance of standard GSH (Sigma, USA), and presented as mg in one gram of hemoglobin (mg/ $\mathrm{gHb}$ ) from $\mathrm{CBC}$ analysis.

The Malondialdehyde (MDA) was evaluated by the protocol of High-Performance Liquid Chromatography (HPLC) [47] using the Thiobarbituric Acid Reactive Substances (TBARS) test. The $200 \mu \mathrm{L}$ of plasma, $750 \mu \mathrm{l}$ of ortho-phosphoric acid (2.5\% v/v) and $200 \mu \mathrm{l}$ of TBA $(0.2 \mathrm{~mol} / \mathrm{L})$ solution were mixed before heating at $90^{\circ} \mathrm{C}$ for 30 min. A clear supernatant of MDA-TBA adduct was separated by centrifugation at 10,000 rpm for 3 minutes before injected into the rheodyne valve with a $10 \mu \mathrm{L}$ fixed loop, and the peak of MDA-TBA adduct was identified at $532 \mathrm{~nm}$ by a C-18 reverse-phase column under an isocratic methanol (pure HPLC grade) mobile phase, with a flow rate of $1.0 \mathrm{~mL} / \mathrm{min}$. The MDA concentration was calculated by comparing with standard tetramethoxypropane (TMP) (Sigma, USA).

PrOOH was evaluated by following the previous protocol [32]. $200 \mu \mathrm{L}$ of plasma was precipitated with $500 \mu \mathrm{L}$ of percholic acid in a cool room for $5 \mathrm{~min}$. The protein pellet was separated by centrifugation at $6,000 \mathrm{rpm}$ for $5 \mathrm{~min}$ before resolved with $700 \mu \mathrm{L}$ of guanidine hydrochloride $(6.0 \mathrm{M})$. Finally, $40 \mu \mathrm{L}$ of perchloric acid $(0.5 \mathrm{M}), 25 \mu \mathrm{L}$ of xylenol orange $(5.0 \mathrm{mM})$, and $10 \mu \mathrm{L}$ of ferrous solution were added. The whole mixture was incubated for 30 min in a dark room before being short centrifuged at 10,000 rpm. The PrOOH was determined by spectrophotometry at $560 \mathrm{~nm}$ and calculated the concentration by compared to standard tert-Butyl hydroperoxide (Sigma, AU).

NO was evaluated by Griess reagent as per Promega's Instructions in a previous protocol [33]. Fresh plasma at $200 \mu \mathrm{L}$ was added to $500 \mu \mathrm{L}$ of N-1-Napthylethylenediamine Dihydrochloride (NED) $(0.1 \%$ in water) and incubated at room temperature in the dark for $5 \mathrm{~min}$. Then, $500 \mu \mathrm{L}$ of sulfanilamide $(1.0 \%$ in $5.0 \%$ phosphoric acid) was added and kept in the dark again for 5 min. A slightly pink color was obtained and read by spectrophotometry at $520 \mathrm{~nm}$. The NO concentration was calculated by comparing with standard sodium nitrite $\left(\mathrm{NaNO}_{3}\right)$ (Sigma, USA).

\section{Multi-Vitamin Evaluation}

In the VitC analysis protocol [39], $100 \mu \mathrm{L}$ of fresh plasma was precipitated with $400 \mu \mathrm{L}$ of $60 \%$ ethanol containing $1 \mathrm{mM}$ of EDTA. After incubation in a cool room $\left(4^{\circ} \mathrm{C}\right)$ for $10 \mathrm{~min}, 200 \mu \mathrm{L}$ of clear supernatant was separated by ultra-centrifugation at $12,000 \mathrm{rpm}$ for $3 \mathrm{~min}$ in order to evaporate by exposure to nitrogen. $10 \mu \mathrm{L}$ of samples were injected into the HPLC composed of a C-18 reversephase column and $2 \%$ acetic acid in water (HPLC grade) as a mobile phase, with a flow rate of $1.0 \mathrm{~mL} / \mathrm{min}$. The peak of Vit $\mathrm{C}$ was identified at $245 \mathrm{~nm}$ by comparing to that of standard ascorbic acid.

For Vit E and A protocols [38], mixing $200 \mu \mathrm{L}$ of hexane with 100 $\mu \mathrm{L}$ of plasma and shaking vigorously for $5 \mathrm{~min}$ before centrifuging at $12,000 \mathrm{rpm}$ for $5 \mathrm{~min}$ in a cool room. $100 \mu \mathrm{L}$ of clear supernatant was separated and evaporated by a speed vacculator for approximately $2 \mathrm{~h}$ and then kept in a refrigerator. Before identifying Vit $\mathrm{A}$ and $\mathrm{E}$, $100 \mu \mathrm{L}$ of ethanol was added. $10 \mu \mathrm{L}$ of the mixture was injected into the HPLC composed of a C-18 reverse-phase column $(250 \times 4.6 \times 5.0$ $\mathrm{mm}$, Phenomenex) and a mixed solution (methanol-acetonitrile and tetrahydrofuran; 75:20:5,v:v:v) as a mobile phase, with a flow rate of $1.2 \mathrm{~mL} / \mathrm{min}$. The peaks of Vit A and E were identified at 325 and $294 \mathrm{~nm}$, respectively, by comparing with those of standards (Sigma).

\section{Inflammatory Cytokine Determination}

The plasma concentration of TNF- $\alpha$, IL-23, and IL-2 was determined using the sandwich ELISA technique (Quantikine ${ }^{\circledR}$, R\&D systems, Inc, Minneapolis, MN, USA) and expressed as units in $\mathrm{pg} / \mathrm{mL}$. The protocols for determining the TNF- $\alpha$, IL-2 and IL23 in plasma were performed by following the Quantikine, Human TNF- $\alpha$, IL-2 and IL-23 Immunoassay guideline. $100 \mu \mathrm{L}$ of plasma was loaded onto an anti- TNF- $\alpha$, anti-IL-2, or anti-IL-23 polyclonal antibody-immobilized solid phase, respectively. After incubating for $2 \mathrm{~h}$ at room temperature and washing 4 times with $400 \mu \mathrm{L}$ of washing buffer, Horseradish Peroxidase (HRP) conjugated with TNF- $\alpha$, IL-2 or IL-23 solutions was added to each respective well before incubating at room temperature for $2 \mathrm{~h}$. After gently aspirating and washing 3 times with washing buffer, $400 \mu \mathrm{L}$ of Tetramethylbenzidine (TMB) substrate was added to develop a 
blue color after incubating for $20 \mathrm{~min}$ at room temperature. In the penultimate step, $50 \mu \mathrm{L}$ of sulfuric acid ( $2 \mathrm{~N}$ ) was used in order to stop the reaction. A yellow color was presented and absorbance read at $450 \mathrm{~nm}$ within $30 \mathrm{~min}$. Finally, the concentration of TNF- $\alpha$, IL-2 and IL-23 in plasma was calculated by comparing with the standard curve of standard TNF- $\alpha$, IL-2 and IL-23, respectively.

\section{Evaluation of Physical Function}

The 6-Minute Walking Test (6MWT) is a standardized simple and safe protocol for evaluating physical function conducted in accordance with the American Thoracic Society protocol in 2002 [48]. But the distance of $20 \mathrm{~m}$ straight line was modified in this protocol. The participants were not permitted to undertake any vigorous activities or eat within 2 hours before testing. All elderly subjects were asked to wear appropriate clothes and shoes. Vital signs such as respiratory rate, oxygen saturation, heart rate, and blood pressure were evaluated before and after the test for safety reasons, which included criteria for precaution or contraindication for the test according to guidelines of the American College Society of Medicine in 2004 [49].

\section{Statistical Analysis}

In vitro results from the concentrations of multi-vitamins, total phenolics, $50 \%$ inhibition (IC50) of radicals, and inflammatory response were presented with the mean and Standard Error of Mean (SEM). In studying the elderly, all parameters were presented in three periods with the mean and Standard Error of Mean (SEM) as well as statistical analysis using the repeated measurement of one-way ANOVA, with a Bonferroni post hoc correction test, whereas, the correlation between all parameters and the 6MWD was determined by the Pearson Correlation test. Statistical analysis was performed using the Statistical Package for Social Sciences, Version 10.0 (SPSS Inc, Chicago, IL, USA). Significance was set at $\mathrm{p}=0.05$. Moreover, and the $\mathrm{G}^{*}$ Power (3.1.9.2) was used to analyze the effect size of the oxidative stress, vitamins, lipid profiles, proinflammatory cytokines, and 6MWD parameters in this study.

\section{Results}

\section{Bioactive Compounds and Free Radical Scavenging Activity}

Screening activities and active compounds of sapodilla extract at $100 \mathrm{~g}$ showed interesting results from scavenging many free radicals in vitro. Determination of the HPLC yield found various compounds such as total phenolics, and Vit A and C. Table 1 shows the dominant yield of Vit C $(13.05 \pm 2.65 \mathrm{mg})$, and lower yield of Vit A $(4.87 \pm 0.98 \mu \mathrm{g})$ in $100 \mathrm{~g}$ of extract, and total phenolics (1.89 $\pm 1.09 \mu \mathrm{g}$ equivalent to Gallic acid/mg sapodilla extract), whereas, this study could not detect Vit E. In addition, the scavenging activity of sapodilla extract showed sequenced activity on hydroxyl $\left(\mathrm{OH}^{\circ}\right)$ and superoxide $\left(\mathrm{O}_{2}{ }^{\circ}\right)$, and non-radicals, such as Nitric Oxide (NO) and Hydrogen Peroxide $\left(\mathrm{H}_{2} \mathrm{O}_{2}\right)$ with an inhibitory concentration of 50 percent (IC50\%) at $8.22 \pm 1.32,33.78 \pm 2.21,22.95 \pm 3.78 \mathrm{mg}$, and $54.49 \pm 2.41$, respectively.

Table 1: Free radical scavenging and active compounds in Sapodilla extracts.

\begin{tabular}{|c|c|}
\hline Active compounds & Concentration \\
\hline Total phenolics & $1.89 \pm 1.09 \mu \mathrm{g}$ Gallic acid per $1 \mathrm{mg}$ extract \\
\hline Vitamin A & $4.87 \pm 0.98 \mu \mathrm{g}$ per $100 \mathrm{~g}$ extract \\
\hline Vitamin E & ND \\
\hline Vitamin C & $13.05 \pm 2.65 \mathrm{mg}$ per 100 g extract \\
\hline Scavenging activity & $33.78 \pm 2.21 \mathrm{mg}$ \\
\hline Superoxide radicals & $8.22 \pm 1.32 \mathrm{mg}$ \\
\hline Hydroxyl radicals & $54.49 \pm 2.41 \mathrm{mg}$ \\
\hline Hydrogen peroxide & $22.95 \pm 3.78 \mathrm{mg}$ \\
\hline Nitric Oxide & IC \\
\hline
\end{tabular}

Note: Values are mean (SEM). IC = inhibitory concentration at $50 \%, \mathrm{ND}=$ not detected

\section{Anti-Inflammatory Response in Human PBMC}

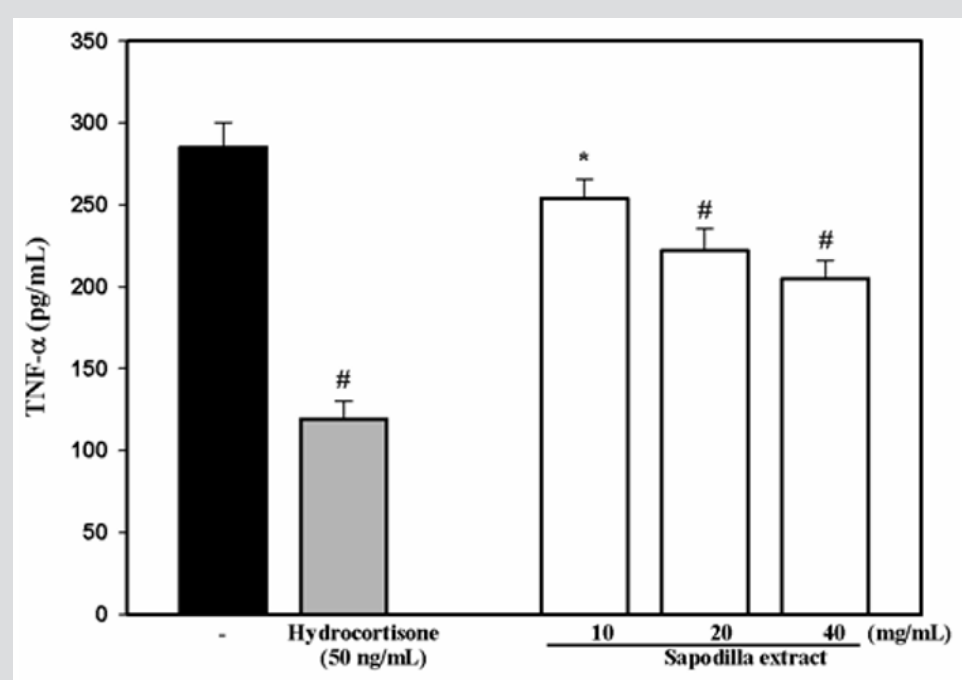

Figure 1: TNF-a levels (pg/mL) released from PBMC (106 cell) and activated by LPS $(1 \mu \mathrm{g} / \mathrm{mL})$ that is untreated or a cell control (back color bar) and treated with hydrocortisone $(50 \mathrm{ng} / \mathrm{mL}$ ) (gray color bar) and Sapodilla extracts at 10, 20, and 40 $\mathrm{mg} / \mathrm{mL}$ (white color bars). ${ }^{*} \mathrm{p}<0.05$, and \# $\mathrm{p}<0.001$ when compared to the cell control (LPS-activated PBMC). 
The anti-TNF- $\alpha$ released in LPS-activated PBMC cells from the experimental study that shows the series response of sapodilla extracts at 10,20 , and $40 \mathrm{mg} / \mathrm{mL}$, when compared to the LPS-activated PBMC cells (Figure 1). Results showed the significantly dominant TNF- $\alpha$ levels released from PBMC cells after activation with LPS for $24 \mathrm{hr}(285.25 \pm 15.34 \mathrm{pg} / \mathrm{mL})$. After treatment with sapodilla extracts at $10 \mathrm{mg} / \mathrm{mL}$, TNF- $\alpha$ showed a significant decrease to Anti-Oxidation in Elderly Individuals

Table 2: Demographic characteristics, Complete Blood Count (CBC), and Liver Function Test (LFT) of 27 elderly individuals.

\begin{tabular}{|c|c|c|c|c|c|}
\hline \multicolumn{6}{|c|}{ Characteristic } \\
\hline Age & (years) & \multicolumn{4}{|c|}{$75.23 \pm 6.23(62-78)$} \\
\hline Weight & $(\mathrm{Kg})$ & \multicolumn{4}{|c|}{$55.45 \pm 3.14(45-65)$} \\
\hline Height & $(\mathrm{m})$ & \multicolumn{4}{|c|}{$1.56 \pm 0.62(1.45-1.69)$} \\
\hline \multirow{2}{*}{ CBC/ LFT } & \multirow{2}{*}{ Reference range } & \multicolumn{2}{|c|}{ Control period } & \multirow{2}{*}{$\begin{array}{l}\text { After } 4 \text { weeks } \\
\text { consumption }\end{array}$} & \multirow{2}{*}{$\mathbf{P}$} \\
\hline & & Week 0 & Week 2 & & \\
\hline WBC & Men $=5-10\left(10^{3} / \mathrm{mL}\right)$ & $\begin{array}{c}6.47 \pm 1.25 \\
(3.2-9.9)\end{array}$ & $\begin{array}{c}6.55 \pm 1.34 \\
(3.5-8.4)\end{array}$ & $\begin{array}{c}6.32 \pm 1.21 \\
(3.5-7.9)\end{array}$ & 0.62 \\
\hline $\mathrm{RBC}$ & $3.8-5.3\left(10^{6} / \mathrm{mL}\right)$ & $\begin{array}{c}4.43 \pm 0.32 \\
(3.5-4.5)\end{array}$ & $\begin{array}{c}4.32 \pm 0.45 \\
(2.32-5.67)\end{array}$ & $\begin{array}{c}4.42 \pm 0.54 \\
(2.44-5.89)\end{array}$ & 0.89 \\
\hline $\mathrm{Hb}$ & $10-16(\mathrm{gm} / \mathrm{dL})$ & $\begin{array}{l}11.98 \pm 1.45 \\
(10.5-15.5)\end{array}$ & $\begin{array}{c}12.78 \pm 1.54 \\
(7.2-15.9)\end{array}$ & $\begin{array}{c}12.08 \pm 1.76 \\
(7.9-15.5)\end{array}$ & 0.51 \\
\hline Hct & $36-50(\%)$ & $\begin{array}{c}40.2 \pm 1.85 \\
(36.0-49.5)\end{array}$ & $\begin{array}{l}37.78 \pm 5.36 \\
(21.0-50.4)\end{array}$ & $\begin{array}{l}37.85 \pm 4.32 \\
(20.8-51.2)\end{array}$ & 0.67 \\
\hline PLT & $140-440\left(10^{3} / \mathrm{mL}\right)$ & $\begin{array}{c}238 \pm 44 \\
(150-430)\end{array}$ & $\begin{array}{c}243 \pm 56 \\
(89-445)\end{array}$ & $\begin{array}{c}248 \pm 61 \\
(92-456)\end{array}$ & 0.64 \\
\hline AST & $10-42(\mathrm{U} / \mathrm{L})$ & $\begin{array}{c}16.62 \pm 0.60 \\
(12-23)\end{array}$ & $\begin{array}{c}1.10 \pm 0.51 \\
(11-21)\end{array}$ & $\begin{array}{c}16.2 \pm 0.67 \\
(10-24)\end{array}$ & 0.17 \\
\hline ALT & $10-40(\mathrm{U} / \mathrm{L})$ & $\begin{array}{c}17.41 \pm 0.59 \\
(12-24)\end{array}$ & $\begin{array}{c}18.15 \pm 0.47 \\
(13-23)\end{array}$ & $\begin{array}{c}17.22 \pm 0.48 \\
(11-23)\end{array}$ & 0.41 \\
\hline
\end{tabular}

Note: $\mathrm{WBC}=$ white blood cells, $\mathrm{RBC}=$ red blood cells, $\mathrm{Hb}=$ haemoglobin, $\mathrm{Hct}=$ haematocrit, $\mathrm{PLt}=$ platelet. $\mathrm{LFT}=$ liver function test, AST $=$ aspartate transaminase, ALT = alanine transaminase. Values are mean (SEM); range for each variable is indicated below in parameters. P value was analyzed statistically with a repeated measurement of one-way ANOVA analysis.

Table 3: Oxidative stress and Vitamins of all 27 elderly individuals.

\begin{tabular}{|c|c|c|c|c|c|}
\hline \multirow{2}{*}{$\begin{array}{l}\text { Oxidative stress } \\
\text { status/Vitamins }\end{array}$} & \multicolumn{2}{|c|}{ Control period } & \multirow{2}{*}{$\begin{array}{l}\text { After } 4 \text { weeks } \\
\text { consumption }\end{array}$} & \multirow{2}{*}{$\mathbf{P}$} & \multirow{2}{*}{ Effect size } \\
\hline & Week 0 & Week 2 & & & \\
\hline TAC (mmol Trolox/L) & $\begin{array}{c}1.01 \pm 0.04 \\
(0.76-1.85)\end{array}$ & $\begin{array}{c}0.99 \pm 0.02 \\
(0.78-1.34)\end{array}$ & $\begin{array}{c}1.40 \pm 0.04 \\
(1.11-2.15)\end{array}$ & $0.00^{*}$ & 0.98 \\
\hline GSH (mg/g Hb) & $\begin{array}{c}14.23 \pm 0.27 \\
(12.12-17.12)\end{array}$ & $\begin{array}{c}15.07 \pm 0.29 \\
(12.12-18.67)\end{array}$ & $\begin{array}{c}15.28 \pm 0.36 \\
(11.23-18.56)\end{array}$ & 0.53 & 0.3 \\
\hline MDA (mmol/L) & $\begin{array}{c}10.12 \pm 0.33 \\
(6.5-13.5)\end{array}$ & $\begin{array}{l}9.67 \pm 0.27 \\
(6.5-12.5)\end{array}$ & $\begin{array}{l}8.93 \pm 0.25 \\
(5.5-11.4)\end{array}$ & $0.02 *$ & 0.81 \\
\hline PrOOH (mmol/L) & $\begin{array}{l}4.23 \pm 0.19 \\
(2.5-6.5)\end{array}$ & $\begin{array}{l}4.01 \pm 0.21 \\
(2.5-6.0)\end{array}$ & $\begin{array}{c}3.80 \pm 0.25 \\
(2.1-5.5)\end{array}$ & 0.27 & 0.41 \\
\hline $\mathrm{NO}(\mu \mathrm{mol} / \mathrm{L})$ & $\begin{array}{l}11.71 \pm 0.37 \\
(7.5-14.5)\end{array}$ & $\begin{array}{l}12.05 \pm 0.35 \\
(8.5-16.4)\end{array}$ & $\begin{array}{l}9.83 \pm 0.30 \\
(6.5-12.5)\end{array}$ & $0.00^{*}$ & 0.95 \\
\hline Vit C (mg/dL) & $\begin{array}{c}0.19 \pm 0.05 \\
(0.05-1.10)\end{array}$ & $\begin{array}{c}0.17 \pm 0.05 \\
(0.04-0.91)\end{array}$ & $\begin{array}{c}3.09 \pm 0.15 \\
(1.2-4.6)\end{array}$ & $0.00^{*}$ & 0.99 \\
\hline Vit A $(\mu \mathrm{g} / \mathrm{mL})$ & $\begin{array}{c}0.32 \pm 0.12 \\
(0.15-0.51)\end{array}$ & $\begin{array}{c}0.28 \pm 0.18 \\
(0.17-0.58)\end{array}$ & $\begin{array}{c}0.54 \pm 0.21 \\
(0.35-0.75)\end{array}$ & $0.00^{*}$ & 0.55 \\
\hline Vit E $(\mu \mathrm{g} / \mathrm{mL})$ & $\begin{array}{c}1.45 \pm 0.08 \\
(0.66-2.23)\end{array}$ & $\begin{array}{c}1.32 \pm 0.08 \\
(0.67-2.28)\end{array}$ & $\begin{array}{c}1.35 \pm 0.07 \\
(0.75-2.23)\end{array}$ & 0.48 & 0.19 \\
\hline
\end{tabular}

Note: Values are mean (SEM); range for each parameter is indicated below in parentheses. TAC = total antioxidant capacity, GSH $=$ glutathione, $\mathrm{MDA}=$ malondialdehyde, $\mathrm{PrOOH}=$ protein hydroperoxide, $\mathrm{NO}=$ nitric oxide, Vit $=$ Vitamin. $\mathrm{P}$ value was analyzed statistically with a repeated measurement of one-way ANOVA analysis. ${ }^{*} \mathrm{p}<0.05$, and NA= non-assessed. Effect size was calculated with a $G^{*}$ Power 3.1.9.2. 
From the completely 27 elderly individuals, (21 men and 6 women) aged between 62 and 78 years (75.23 \pm 6.23 years) completed this study. The results of $\mathrm{CBC}$ and liver function during the control and after the consumption periods showed no statistical difference (Table 2). Table 3 shows the results of oxidative stress and plasma vitamins, and the oxidative status within the control period presents a non-significant change in TAC ( $p=1.00)$, GSH ( $p=0.45), \operatorname{MDA}(\mathrm{p}=1.00), \operatorname{PrOOH}(\mathrm{p}=0.25)$, and NO ( $\mathrm{p}=0.46)$. After consumption of sapodilla at $100 \mathrm{~g}$ for 4 weeks, no statistical changes occurred in GSH or PrOOH. However, TAC increased significantly when compared to week $0(\mathrm{p}=0.000)$ and week $2(\mathrm{p}$ $=0.000$ ). While MDA reduced significantly when compared to week $0(\mathrm{p}=0.025)$, it reduced non-significantly when compared to week $2(p=0.24)$. Finally, the level of NO decreased significantly when compared to week $0(p=0.001)$ and week 2 in the control period $(\mathrm{p}=0.000)$ (Figure 2).

\section{Multi-Vitamins in Elderly Individuals}

Figure 2 and Table 3 show a significant increase of Vit $\mathrm{C}$ level from results of the vitamin plasma analysis after sapodilla consumption when compared to week $0(p=0.000)$ and week 2 $(\mathrm{p}=0.000)$. In addition, the Vit A level also increased after 4 weeks consumption when compared to week $0(\mathrm{p}=0.000)$ and week $2(\mathrm{p}$ $=0.000$ ) of the control period. Whereas, no change occurred in the level of Vit E between week 0, week 2, and week 6 ( $p=0.48)$.
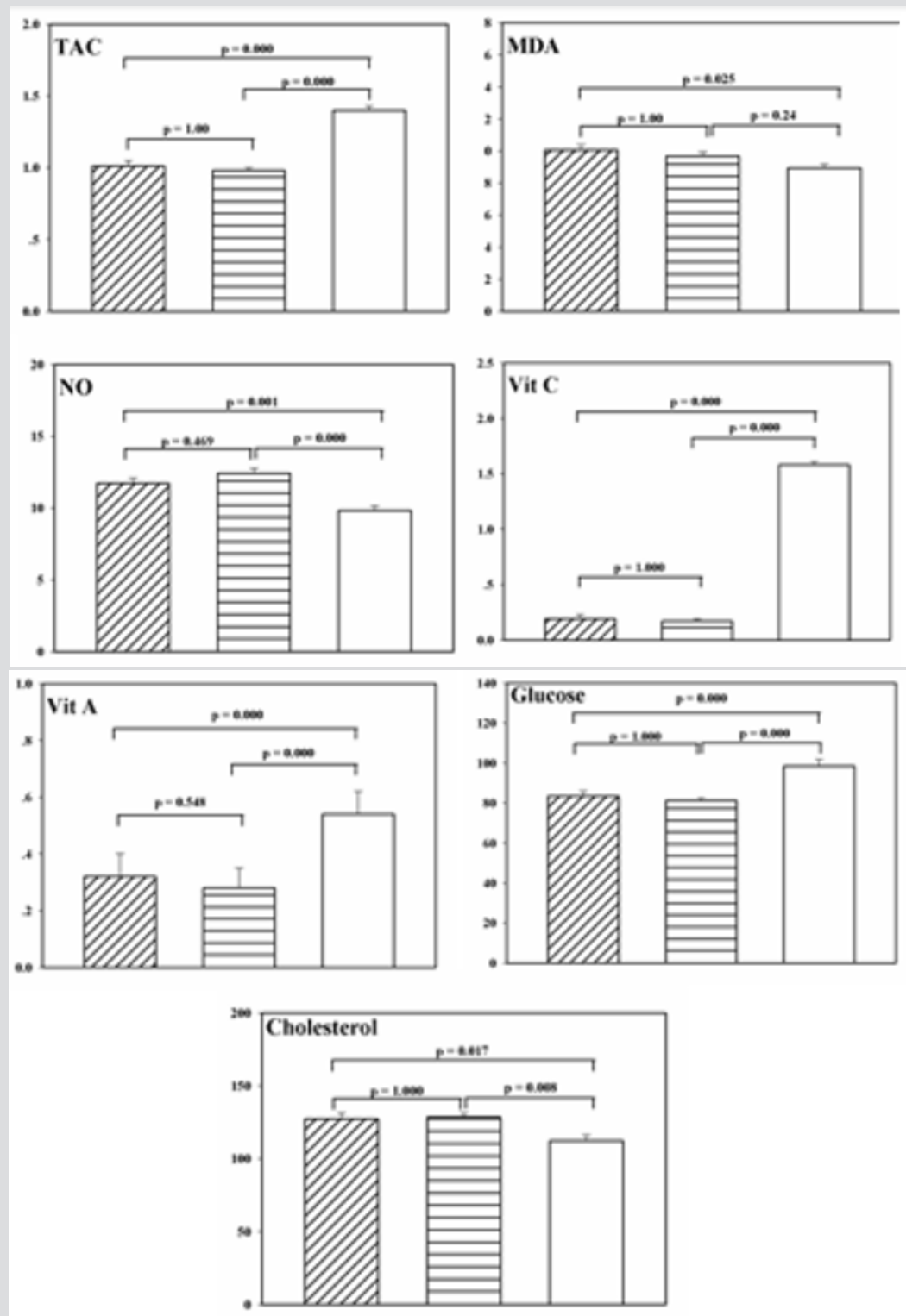

Figure 2: TAC (mmol Trolox/L), MDA ( $\mu \mathrm{mol} / \mathrm{L})$, NO ( $\mu \mathrm{mol} / \mathrm{L})$, vit $\mathrm{C}(\mathrm{mg} / \mathrm{mL})$, vit A $(\mu \mathrm{g} / \mathrm{mL})$, glucose $(\mathrm{mg} / \mathrm{dL})$ and cholesterol $(\mathrm{mg} / \mathrm{dL})$ of all 27 elderly subjects during the control period (oblique bar = week 0, horizontal bar = week 2) and after sapodilla consumption for 4 weeks (white bar). Each bar represents the mean and Standard Error of Mean (SEM). Oneway ANOVA and Bonferroni tests were used for statistical analysis. 


\section{Lipid Profiles in Elderly Individuals}

No statistical difference was seen in triglyceride $(p=0.72)$, HDL-C ( $p=0.14)$, or LDL ( $p=0.10)$ levels in three repeated measurements during the 6 week study (Table 4). Whereas, the results of cholesterol level showed a significant decrease after
4 weeks of sapodilla consumption when compared to week 0 (p $=0.017)$ and week $2(p=0.008)$ of the control period. Moreover, the glucose concentration showed a significant increase after consumption, when compared to week $0(p=0.000)$ and week $2(p$ $=0.000$ ), while no statistical difference was seen within the control period $(\mathrm{p}=1.00)$ (Figure 2).

Table 4: Glucose and Lipid profiles of all 27 elderly individuals.

\begin{tabular}{|c|c|c|c|c|c|}
\hline & \multicolumn{2}{|c|}{ Control period } & \multirow{2}{*}{$\begin{array}{l}\text { After } 4 \text { weeks } \\
\text { consumption }\end{array}$} & \multirow{2}{*}{$\mathbf{P}$} & \multirow{2}{*}{ Effect size } \\
\hline & Week 0 & Week 2 & & & \\
\hline Glucose (mg/dL) & $\begin{array}{c}83.50 \pm 2.55 \\
(67-109) \\
\end{array}$ & $\begin{array}{c}81.20 \pm 1.30 \\
(78-112)\end{array}$ & $\begin{array}{c}98.48 \pm 3.19 \\
(79-133)\end{array}$ & $0.00^{*}$ & 0.96 \\
\hline Triglyceride (mg/dL) & $\begin{array}{c}129.18 \pm 3.81 \\
(78-159)\end{array}$ & $\begin{array}{c}125.11 \pm 3.67 \\
(85-157)\end{array}$ & $\begin{array}{c}126.96 \pm 3.05 \\
(85-158)\end{array}$ & 0.72 & 0.26 \\
\hline Cholesterol (mg/dL) & $\begin{array}{c}127.07 \pm 4.27 \\
(90-178)\end{array}$ & $\begin{array}{c}128.56 \pm 2.74 \\
(95-165)\end{array}$ & $\begin{array}{c}112.29 \pm 3.82 \\
(85-156)\end{array}$ & $0.00^{*}$ & 0.92 \\
\hline HDL-C (mg/dL) & $\begin{array}{c}42.74 \pm 1.58 \\
(30-56)\end{array}$ & $\begin{array}{c}43.37 \pm 1.62 \\
(31-58)\end{array}$ & $\begin{array}{c}46.81 \pm 1.45 \\
(35-56)\end{array}$ & 0.14 & 0.74 \\
\hline LDL (mg/dL) & $\begin{array}{c}105.3 \pm 2.01 \\
(85-120)\end{array}$ & $\begin{array}{c}106.67 \pm 1.95 \\
(86-122)\end{array}$ & $\begin{array}{c}100.69 \pm 2.17 \\
(76-120)\end{array}$ & 0.1 & 0.82 \\
\hline
\end{tabular}

Note: Values are mean (SEM); range for each parameter is indicated below in parentheses. HDL-C = high-density lipoproteincholesterol, LDL= low-density lipoprotein. P value was analyzed statistically with a repeated measurement of one-way ANOVA analysis. ${ }^{*} \mathrm{p}<0.05$. NA = non-assessed. Effect size was calculated with a G*Power 3.1.9.2.

\section{Inflammatory Cytokines and 6MWD}

Results from 6 weeks of experiments and three repeated analyses showed no statistical difference in any cytokines (Table 5); TNF- $\alpha(p=0.81)$, IL-23 ( $p=0.93)$ or IL-2 ( $p=0.59)$. Data from the 6MWD test showed no statistical difference within 2 weeks in the control period ( $p=0.18$ ). However, after 4 weeks of sapodilla consumption, a significant increase was seen when compared to week $0(p=0.000)$ and week $2(p=0.000)$.

Table 5: Pro-inflammatory cytokines and 6MWD parameters of all 27 elderly individuals.

\begin{tabular}{|c|c|c|c|c|c|}
\hline \multirow{2}{*}{ Cytokines } & \multicolumn{2}{|c|}{ Control period } & \multirow{2}{*}{$\begin{array}{l}\text { After 4-weeks } \\
\text { consumption }\end{array}$} & \multirow{2}{*}{$\mathbf{P}$} & \multirow{2}{*}{ Effect size } \\
\hline & Week 0 & Week 2 & & & \\
\hline TNF-a (pg/mL) & $\begin{array}{c}8.13 \pm 0.21 \\
(5.12-9.33)\end{array}$ & $\begin{array}{c}7.96 \pm 0.20 \\
(6.12-10.12) \\
\end{array}$ & $\begin{array}{c}8.23 \pm 0.29 \\
(5.50-11.13) \\
\end{array}$ & 0.81 & 0.47 \\
\hline IL-23 (pg/mL) & $\begin{array}{c}9.10 \pm 0.41 \\
(5.12-18.12)\end{array}$ & $\begin{array}{c}8.95 \pm 0.41 \\
(4.67-17.23) \\
\end{array}$ & $\begin{array}{c}9.15 \pm 0.43 \\
(3.34-16.12)\end{array}$ & 0.93 & 0.23 \\
\hline IL-2 (pg/mL) & $\begin{array}{c}3.78 \pm 0.23 \\
(1.21-6.31) \\
\end{array}$ & $\begin{array}{c}4.11 \pm 0.22 \\
(1.92-7.12)\end{array}$ & $\begin{array}{c}3.89 \pm 0.21 \\
(1.23-5.65) \\
\end{array}$ & 0.59 & 0.45 \\
\hline 6MWD (m) & $\begin{array}{l}363.5 \pm 8.4 \\
(300-425)\end{array}$ & $\begin{array}{l}340.1 \pm 8.9 \\
(280-448)\end{array}$ & $\begin{array}{l}422.5 \pm 8.7 \\
(325-500)\end{array}$ & $0.00^{*}$ & 0.97 \\
\hline
\end{tabular}

Note: Values are mean (SEM); range for each parameter is indicated below in parentheses. TNF = tumor necrosis factor, IL = interleukin, $6 \mathrm{MWD}=6$-minute walking distance. P value was analyzed statistically with a repeated measurement of one-way ANOVA analysis. ${ }^{*} \mathrm{p}<0.05 . \mathrm{NA}=$ non-assessed. Effect size was calculated with a $\mathrm{G}^{*}$ Power 3.1.9.2.

\section{Discussion}

The ratio of the elderly population in Thailand is growing, as indicated in the introduction and prior literature review (Mahidol University Population projections for Thailand 2005-2025) [1]. Although sapodilla fruit is not available all year round, as are oranges, bananas, etc., it is still popular in Thailand and elsewhere for its delicious and sweet taste. However, there has been little evidence that sapodilla yields benefits to elderly persons. Therefore, this study was designed for testing the effects of this fruit on both elderly subjects and in vitro. Thus, oxidative stress, antioxidants, lipid profile, inflammatory cytokines, and physical function from fresh sapodilla consumption were applied, in the same way as that for confirming identification of active compounds and antiinflammatory response in PBMC cells from sapodilla extract.
The results of this study identified the main active compounds as total phenolics, Vit A, Vit E, and Vit C and found a higher concentration of Vit C than Vit A in sapodilla extract. The yield of Vit $\mathrm{C}$ and $\mathrm{A}$ in $100 \mathrm{~g}$ of sapodilla was $13.05 \pm 2.65 \mathrm{mg}$ and $4.87 \pm 0.98 \mu \mathrm{g}$, respectively, which is similar to that in the USDA database $14.7 \mathrm{mg}$ $\& 3.0 \mu \mathrm{g}$ ), but lower than that in a report on nutritional facts of Thai fruit (18 $\mathrm{mg}$ of vitamin $\mathrm{C}$ ). Moreover, results showed the radical scavenging activity of $\mathrm{OH}^{\circ}, \mathrm{NO}, \mathrm{O}_{2}{ }^{\circ-}$, and $\mathrm{H}_{2} \mathrm{O}_{2}$, which corresponded to previous evidence [40], that Vit $\mathrm{C}$ actively reduced power and free radical scavenging on the $\mathrm{O}_{2}{ }^{\circ}$ and $\mathrm{NO}$, and also inhibited lipid peroxidation in vitro. Furthermore, active compounds, such as polyphenol, also present antioxidant activity [31,50,51].

Previous evidence has confirmed strongly that $-\mathrm{OH}$ substitution in the ring of flavones relates to antioxidant activity 
[52]. Whereas, the strength of antioxidant activity in Vit A is not as strong as that in Vit $\mathrm{C}$, which is summarized in a previous report as having the function of vision, and normal or epithelial cell growth [53]. However, previous evidences have shown an enhancing antioxidant defense function [54,55]. In addition, clearly significant investigation on the antioxidant activities of vitamin-containing plants or functional food has shown that both Vit A and C can scavenge free radicals and $\mathrm{H}_{2} \mathrm{O}_{2}$ [56]. Therefore, this study presents some active compounds such as Vit $\mathrm{C}$ and total phenol, as well as Vit $\mathrm{A}$ that possibly relate to the antioxidant and radical scavenging activities in sapodilla extracts.

Results of the TNF- $\alpha$ release from the LPS-activated PBMC model showed the significant activity of sapodilla extract in a dosedependent manner as in Figure 1. These results showed a significant depression of TNF- $\alpha$ releases after $24 \mathrm{~h}$ incubation, which is the same for hydrocortisone that is an important glucocorticoid and has anti-inflammatory and immunosuppressive properties [57]. A previous report showed that flavonoid in tricin rice was able to inhibit the activity of pro-inflammatory mediators through NF$\mathrm{kB}$ signaling in mononuclear cells [45] as same as the retinoid (Vit A) activity in LPS-induced PBMC cells in vitro [58]. Thus, the mechanism of sapodilla extract could possibly inhibit the TNF- $\alpha$ release from phenolic and vitamin function by scavenging free radicals in the LPS-induced PBMC model.

Because only 30 elderly subjects were included in this study, possibly less power if they were divided into two groups with control and study groups. Thus, the self-controlled condition by a within-subject had been designed with a 2-weeks of control period and then experiment for 4 weeks. From the demographic characteristics of all the elderly subjects, who had a mean age of $75.23 \pm 6.23$ years, and all parameters; White Blood Cells (WBC), Red Blood Cells (RBC), Haemoglobin (Hb), Haematocrit (Hct) and Platelet (PLT) were tested within a control period and repeated after sapodilla consumption, there was no statistical difference that can possibly claim as no adverse effects from supplementation.

From the results of oxidative stress status and vitamins when comparing between the repeated measurement of ANOVA analysis within the three periods, and they indicated that GSH, PrOOH, and Vit E levels were no different, whereas, TAC, MDA, NO, Vit $C$, and Vit A showed a significant difference. When statistical analysis was calculated with the Bonferroni test within the control period, no parameters were different. Although the results of MDA showed significant changes within the three periods, no significant difference between week 2 and week 6 after sapodilla consumption, thus the level in this result could not conclude the significant difference exactly. From over all of the improvement on TAC results possibly relate to the increased on Vit C and Vit A in plasma. Whereas, Vit E plasma did not change statistically, which possibly relates to the results of unidentifiable Vit E in sapodilla extract. Moreover, from 30 subjects had included in this study, that is possible low sample size, thus the effect size (d) computing had also to confirm the significant or non-significant results in each parameter. Thus, a significant result with a large effect sizes ( $d>0.8$ ) is strongly recommend confirming the good efficiency of protocol or supplementation [59], whereas the statistical results with small $(d=0.2)$ or moderate $(d=0.5)$ effect size should be reassessed or confirmed with a larger sample size. Therefore, the P-value and effect size of TAC, NO, and Vit C in Table 3 presents the significant credible results.

Results of the lipid profile and glucose showed some interesting results. Consumption of sapodilla at $100 \mathrm{~g}$ twice daily for 4 weeks did not affect the concentration of triglyceride, HDL-C, and LDL, but there were effects on cholesterol and glucose levels, as seen from the repeated measurement of ANOVA tests. A non-statistical difference of glucose and cholesterol levels in the control period were shown, but after 4-weeks consumption of sapodilla, the cholesterol level reduced significantly when compared to week 0 and week 2. However, the glucose level increased when compared to week 0 and week 2 . The significant results of glucose and cholesterol also confirmed the significant credible value with a larger effect size $(d>0.8)$. Previous evidence of mechanisms is still controversial, and little has been confirmed as to why fruit can reduce cholesterol or any lipid parameters, especially in elderly subjects. It also has been reported that lowering cholesterol is by means of converting cholesterol into bile acids or inhibiting bile acids of HMG-CoA reductase to lower cholesterol biosynthesis [60]. Previous evidence from a hamster model reported by Chau, et al. (2004) found that isolated water-insoluble fiber-rich fraction from the pomace of star fruit has hypocholesterlemic and hypolipidemic activities in hamster rats [61].

Moreover, the latest evidence has suggested that significant changes occur in HDL and LDL from oxidative stress in hypertension and abnormal lipoprotein [6]. The correlation between antioxidant compounds as Vit C or Vit A and cholesterol results are still controversial discussed that need to be studied in the future. For the results of sapodilla consumption presented a significant increase in glucose level. Although there is no evidence showing enhanced glucose activity after elderly people had consumed sapodilla, and the USDA database had no reports, the nutrient facts of Thai fruit presented in 2010 showed a yield of $17 \mathrm{~g}$ of glucose from $100 \mathrm{~g}$ of sapodilla fruit. Therefore, the increased level of glucose in elderly people is possibly caused by the glucose content in sapodilla fruit. In results of a higher glucose level after supplementation with a significant and larger effect size value should be concerned in clinical administration on elderly people who have a high risk of the insulin resistance condition.

Furthermore, results of inflammatory cytokines also present a non-significant change in TNF- $\alpha$, IL-23, and IL-2. The case of nonsignificant change in the IL-2 level after 4 weeks of sapodilla fruit consumption can be explained by all cytokines being secreted from T-lymphocytes [20,62], and these cell types did not respond to free radicals in the same way as a macrophage or Dendritic Cell (DC), which was last reported to have different stimulatory effects on Natural Killer (NK) cells, Natural Killer T (NK-T) cells, and B cells [63-65]. In addition, a DC and macrophage also release IL-23 and IL12 [21]. A non-statistical difference in HDL-C, LDL, and all cytokines in this study shows a relationship between HDL and inflammatory cytokines, as explained in previous reports. HDL-C can inhibit the inflammatory process via several mechanisms, including promotion of cholesterol efflux, inhibition of LDL oxidation and reduction of 
adhesion molecule expression [66]. Therefore, the results of a nonstatistical change in HDL or LDL possibly relate to non-significance in all cytokines.

This study analyzed the aspect of physical function via the 6MWD test by evaluating functional capacity indoors, because it was simple, inexpensive, and a quick protocol for reflecting capacity in day-to-day activities [67]. The result showed a significant increase in distance between the control period and after sapodilla consumption. The 6MWD between week 0 (363.5 \pm $8.4 \mathrm{~m}$ ) and week $2(340.1 \pm 8.9 \mathrm{~m})$ was not statistically different ( $\mathrm{p}$ = 1.000), but it increased significantly after 4 weeks of sapodilla consumption $(422.5 \pm 8.7 \mathrm{~m})(\mathrm{p}=0.000)$. The possible mechanism of improvement on walking capacity in this study is unclear and cannot conclude exactly, increased walking should positively correlate with the increased NO level as a previous suggestion that has explained by the effects of vasodilatation [68]. This phenomenon helps to increase the flow of blood in the muscle that affects walking tolerance. Furthermore, evidence shows that releasing NO during exercise improves endothelial function [69].

This result also is similar to the previous study of Leelarungrayub, that found the correlation between NO and 6MWD in elderly individuals. In addition, the results also found a significant correlation between glucose level and 6MWD [33]. Moreover, the possibly proposed in previous evidence who discussed the glucose function on muscle contraction during exercise, which provides an energy source for both glycolysis and ATP generative processes during walking [70] that can be possibly applied because of the increased glucose level in elderly persons after consumption in the result of this study. In addition, the study of Neville and co-worker produced interesting results on muscle strength from 39 elderly subjects aged $71.1 \pm 5.0$ years, when comparing different doses of fruit and/or vegetable consumption that ranged between 2 and 5 portions daily for 6 weeks and resulted in a positive correlation between grip strength and Vit $\mathrm{C}$ status. It also proposed that the level of Vit $\mathrm{C}$ depended on the amount of fruit and/or vegetables consumed per day [71], as in cross-sectional evidence of a significant relationship between antioxidant plasma concentration and muscle strength [72-74].

Therefore, the possible mechanism that enables Vit C to help walking ability can be explained from previous reports by Halliwell (2001) [73] and McGinley, et al. (2009) [74], who state that Vit C is also a cofactor for several enzymes during the post-translational hydroxylation of collagen, biosynthesis of carnitine, conversion process of the neurotransmitter, and iron uptake. Then higher levels of Vit $\mathrm{C}$ after consumption is possible effects on exercise capacity in elderly persons, but this also needs to be confirmed the correlation between the Vit C level, the strength of the lower-part muscle performance and walking distance [75].

\section{Conclusion and Limitations}

Overall, this preliminary results showed that consuming sapodilla fruit, which contains vitamin $\mathrm{C}$ and vitamin $\mathrm{A}$, affects Total Antioxidant Capacity (TAC), Nitric Oxide (NO), glucose and cholesterol as well as improving the walking capacity of elderly people. However, additional study with a larger sample size of elderly people should be carried out to confirm these initial findings. Results may provide strong evidence for the widespread use of sapodilla fruit as a functional food for better health in elderly individuals. Regarding the dose for consuming ripe sapodilla fruit at 100 grams after a meal in morning and evening daily in this study should be of concern due to a possible glucose overdose, especially for elderly people with diabetes. It should be noted that not only sapodilla can be adapted to being a supplement, but also orange, grapefruit, kiwifruit, strawberry, cantaloupe, red pepper, green pepper, and tomato, all of which have been shown to benefit the health of the elderly.

\section{Acknowledgement}

The authors gratefully acknowledge the TRF, especially thank all elderly participants and all caregivers at Piyaman Elderly Health Care Center in Chiang Mai province, Thailand for their assistance in helping to organize this study.

\section{References}

1. (2006) Mahidol University Population projections for Thailand 20052025. Institute for population and social research, Mahidol University ( $1^{\text {st }}$ edn.), Andison Press Product. Ltd. Bangkok.

2. Drewnowski A, Shultz JM (2001) Impact of aging on eating behaviors, food choices, nutrition, and health status. J Nutr Health Aging 5: 75-79.

3. Fontana L (2009) Modulating human aging and age-associated diseases. Biochimica et Biophysica Acta 1790: 1133-1138.

4. Junqueria VB, Barros SB, Chan SS, Rodrigues L, Giavarotti L, et al. (2004) Aging and oxidative stress. Mol Aspects Med 25: 5-16.

5. Cutler RG, Rodriguez H (2003) Critical reviews of oxidative stress and aging: Advances in basic science, diagnostics and intervention. World scientific publishing, Singapore, pp. 1523.

6. Kumar A (2014) Correlation between anthropometric measurement, lipid profile, dietary vitamins, serum antioxidants, lipoprotein (a) and lipid peroxides in known case of 345 elderly hypertensive South Asian aged 56-64 y-A hospital based study. Asian Pac J Trop Biomed 4: S189-S197.

7. Yang D, Xie H, Jia X, Wei X [2015] Flavonoid C-glycosides from star fruit and their antioxidant activity. J Funct Foods 16: 204-210.

8. Gianni P, Jan KJ, Douglas MJ, Stuart PM, Tarnopolsky MA (2004) Oxidative stress and the mitochondrial theory of aging in human skeletal muscle. Exp Gerontol 39: 1391-1400.

9. Rynan MJ, Dudash HJ, Docherty M, Geronilla KB, Baker BA, et al. (2008) Aging-dependent regulation of antioxidant enzymes and redox status in chronically loaded rat dorsiflexor muscles. J Gerontol 63: 1015-1026.

10. Holzer M, Trieb M, Konya V, Wadsack C, Heinemann A, et al. (2013) Aging affects high-density lipoprotein composition and function. Biochim Biophys Acta 1831: 1442-1448.

11. Berrougui H, Isabelle M, Cloutier M, Grenier G, Khalil A (2007) Agerelated impairment of HDL-mediated cholesterol efflux. J Lipid Res 48: 328-336.

12. Jaouad L, de Guise C, Berrougui H, Cloutier M, Isabelle M, et al. (2006) Age-related disease in high-density lipoproteins antioxidant activity is due to an alteration in the PON1's free sulfhydryl groups. Atherosclerosis 185: 191-200

13. Bruckert E, Hansel B (2007) HDL-c is a powerful lipid predictor of cardiovascular diseases. Int J Clin Pract 61: 1905-1913.

14. O'Connor JE, Herrera G, Martinez-Romero A, de Oyanguren FS, Diaz L, et al. (2014) Systems biology and immune aging. Immunol Lett 162: 334345 . 
15. Ren JL, Pan JS, Lu YP, Sun P, Han J (2009) Inflammatory signaling and cellular senescence. Cell Signal 21: 378-383.

16. Baylis D, Bartlett DB, Patel HP, Roberts HC (2013) Understanding how we age: Insights into inflammaging. Longev Healthspan 2: 8 .

17. Michaud M, Balardy L, Moulis G, Gaudin C, Peyrot C, et al. (2003) Proinflammatory cytokines, aging, and aged-related diseases. J Am Med Dir Assoc 14: 877-882.

18. Singh T, Newman AB (2011) Inflammatory markers in population studies of aging. Ageing Res Rev 10: 319-329.

19. Hughes DA (1999) Effects of dietary antioxidants on the immune function of middle-aged adults. Proc Nutr Soc 58: 79-84.

20. Mitchell BL, Ulrich CM, McTiernan A (2003) Supplementation with vitamins or minerals and immune function; can the elderly benefit. Nutr Res 23: 1117-1139.

21. Zhou L, Ivanov II, Spolski R, Min R, Shenderov K, et al. (2007) IL-6 programs $\mathrm{T}(\mathrm{H})-17$ cells differentiation by promoting sequentia engagement of the IL-21 and iL-23 pathways. Nat Immunol 8: 967-974.

22. Croxford AL, Kulig P, Becher B (2014) IL-12 and IL-23 in health and disease. Cytokine Growth Factor Rev 25: 415-421.

23. Yawalkar N, Tscharner GG, Hunger RE, Hassan AS (2000) Increased expression of IL-12p70 and IL-23 by multiple dendritic cell and macrophage subsets in plaque psoriasis. J Dermatol Sci 54: 99-105.

24. EI Assar M, Angulo J, Rodriguez-Manas L (2013) Oxidative stress and vascular inflammation in aging. Free Radic Biol Med 65: 380-401.

25. Ferrari CK B (2007) Functional foods and physical activities in health promotion of aging people. Maturitas 58: 327-339.

26. Lopez-Varela S, Gonzalez-Gross M, Marcos A (2002) Functional foods and the immune system: A review. Eur J Clin Nutr 56: S29-S33.

27. Podmore ID, Griffiths HR, Herbert KE, Mistry N, Mistry P, et al. (1998) Vitamin C exhibits pro-oxidant properties. Nature 392: 559.

28. Kennes B, Dumont I, Brohee D, Hubert C, Nerve P (1983) Effect of vitamin $C$ supplementation on cell-mediated immunity in old people. Gerontology 29: 305-310.

29. Raiola A, Tenore GC, Barone A, Frusciante L, Rigano MM (2015) Vitamin E content and composition in Tomato fruits; beneficial roles and biofortification. Inter J Molec Sci 16: 29250-29264.

30. Kean RJ, Lamport DJ, Dood GF, Freeman JE, Williams CM, et al. (2015) Chronic consumption of flavanone-rich orange juice is associated with cognitive benefits; An 8-wk, randomized, double-blind, placebocontrolled trial in healthy older adults. Am J Clin Nutr 101: 506-514.

31. Lim Y, Lim TT, Tee JJ (2007) Antioxidant properties of several tropical fruits: A comparative study. Food Chem 103: 1003-1008.

32. Leelarungrayub J, Yankai A, Pinkaew D, Puntumetakul R, Laskin JJ, et al (2016) A preliminary study on the effects of star fruit consumption on antioxidant and lipid status in elderly Thai individuals. Clin Interv Aging 11: 1183-1192.

33. Leelarungrayub J, Laskin JJ, Bloomer RJ, Pinkaew D (2016) Consumption of star fruit juice on pro-inflammatory markers and walking distance in the community dwelling elderly. Arch Gerontol Geriatr 64: 6-12.

34. United States Department of Agriculture (2015) USDA food composition databases.

35. Barbalho SM, Bueno PC, Delazari DS, Ghuiguer EL, Cogueiro DP, et al (2015) Antidiabetic and antilipidemic effects of Manikara Zapata. J Med Food 18: 385-391.

36. Shui G, Leng LP (2004) Analysis of polyphenolic antioxidants in star fruit using liquid chromatography and mass spectrometry. J Chromatogr A 1022: 67-75.

37. Ma J, Luo XD, Protiva P, Yang H, Ma C, et al. (2003) Bioactive novel polyphenols from the fruit of Manikara zapota (Sapodilla). J Nat Prod 66: 983-986.
38. Talwar D, Ha TK, Cooney J, Brownlee C, O’Reilly DS (1998) A routine method for the simultaneous measurement of retinol, alpha-tocopherol and five carotenoids in human plasma by reverse phase HPLC. Clin Chim Acta 270: 85-100.

39. Furusawa N (2001) Rapid high-performance liquid chromatographic identification/ quantification of total vitamin C in fruit drinks. Food Control 12: 27-29.

40. Zheng W, Wang SY (2001) Antioxidant activity and phenolic compounds in selected herbs. J Agric Food Chem 49: 5165-5170.

41. Hazra B, Biswas S, Manda N (2008) Antioxidant and free radical scavenging activity of Spondias pinnata. BMC Complement Altern Med 8: 63.

42. Wang H, Sun Y, Ye WC, Xiong F, Wu JJ, et al. (2004) Antioxidant capacity of phenolic phytochemicals from various cultivars of plums. Chem Pharm Bull (Tokyo) 52: 615-617.

43. Jha HC, von Recklinghausen G, Zilliken F (1985) Inhibition of in vitro microsomal lipid peroxidation by isoflavonoids. Biochem Phamacol 34: 1367-1369.

44. Sreejayan N, Rao MNA (1994) Curcuminoids as potent inhibitors of lipid peroxidation. J Pharm Pharmacol 46: 1013-1016.

45. Shalini V, Jayalekshmi A, Helen A (2015) Mechanism of anti-inflammatory effect of tricin, a flavonoid isolated from Njavara rice bran in LPS-induced hPBMCs and carrangeenan induced rats. Mol Immunol 66: 229-239.

46. Re R, Pellegrini N, Proteggente A, Pannala A, Yand M, et al. (1999) Antioxidant activity applying an improved ABTS radical cation decolorization assay. Free Radic Biol Med 26: 1231-1237.

47. Chirico S (1994) High-performance liquid chromatograph-based thiobarbituric acid tests. Methods Enzymol 233: 314-318.

48. ATS Committee on Proficiency Standards for Clinical Pulmonary Function Laboratories (2002) ATS statement; guidelines for the sixminute walk test. Am J Respir Crit Care Med 166: 111-117.

49. American College of Sport Medicine (ACSM) (2004) ACSM's guidelines for exercise testing and prescription. Lippincott Williams \&Wilkins, Philadelphia. pp. 110-112.

50. Duan X, Jiang Y, Su X, Zhang A, Shi J (2007) Antioxidant properties of anthocyanins extracted from litchi (Litchi chinenesis Sonn.) fruit pericarp tissues in relation to their role in the pericarp browning. Food Chem 101: 1365-1371.

51. Caillet S, Lorenzo G, Cote J, Sylvain JF, Lacroix M [2012] Free radicalscavenging properties and antioxidant activity of fractions from cranberry products. Food Nutr Sci 3: 337-347.

52. Rice-Evans CA, Miller NJ, Paganga G (1996) Structure-antioxidant activity relationships of flavonoids and phenolic acids. Free Radic Biol Med 20: 933-956.

53. Donoghue S, Kronfeld DS, Berkowitz SJ (1981) Vitamin A nutrition of the equine: growth, serum biochemistry and hematology. J Nutr 111: 365374

54. Ma XM, Yang ZB, Yang MR, Song ML (2005) Effect of different vitamin A levels in diets on antioxidant ability of beef cattle (in Chinese). Chinese J Animal Nutr 17: 31-35.

55. Kleczkowski M, Klucinski W, Sikora J, Zdanowicz M, Dziekan P (2003) Role of the antioxidants in the protection against oxidative stress in cattle-nonenzymatic mechanisms (Part 2). Pol J Vet Sci 6: 301-308.

56. Asensi-Fabada M, Munne-Bosch S (2000) Vitamins in plants: Occurrence, biosynthesis and antioxidant function. Trends Plant Sci 15: 582-592.

57.Stahn C, Buttgereit F (2004) Genomic and nongenomic effects of glucocorticoids. Nat Clin Pract Rheumatol 4: 525-533.

58. Wojtal KA, Wolfram L, Frey-Wagner I, Lang S, Scharl M, et al. (2013) The effects of vitamin A on cells of innate immunity in vitro. Toxicol In Vitro 27: 1525-1532. 
59. Sullivan GM, Feinn R (2012) Using effect size-or why the p value is not enough. J Grad Med Educ 4: 279-282.

60. Jiang J, Zhang K, Qin J, Min X, Zhang L, et al. (2015) Quantitative assessment of the effect of cholesterol on blood glucose measurement using near infrared spectroscopy and a method for error reduction. Lasers Sur Med 47: 88-97.

61. Chau CF, Chen CH, Lee MH (2004) Characterization and physiochemical properties of some potential fibers derived from Averrhoa carambola. Die Nahrung 48: 43-46.

62. Das S, Varalakshmi S, Kumari AL, Patei M, Khar A (2001) Target cell induced activation of NK cells in vitro; cytokine production and enhancement of cytotoxic function. Cancer Immunol Immunother 50 : 428-436.

63. Leonard WJ (2001) Cytokines and immunodeficiency diseases. Nat Rev Immunol 1: 200-208.

64. Paliard X, de Waal Malefijt R, Yssel H, Blanchard D, Chretien I, et al. (1988) Simultaneous production of IL-2, IL-4, and IFN-gamma by activated human CD4+ and CD8+ T cell clones. J Immunol 141: 849-855.

65. Yui MA, Sharp LL, Havran WL, Rothenberg EV (2004) Preferential activation of an IL- 2 regulatory sequence transgene in TCR gamma delta and NKT cells: subset-specific differences in IL-2 regulation. J Immunol 172: 4691-4699.

66. Barter P (2005) The inflammation: Lipoprotein cycle. Atherosclerosis 6 : 15-20.

67. Steffens D, Beckenkamp PR, Hancock M, Paiva DN, Alison JA, et al. (2013) Activity level predicts 60 minute walk distance in healthy older females; an observation study. Physiother 99: 21-26.

\section{ISSN: 2574-1241}

DOI: 10.26717/BJSTR.2019.15.002684

Jirakrit Leelarungrayub. Biomed J Sci \& Tech Res

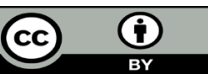

This work is licensed under Creative Commons Attribution 4.0 License

Submission Link: https://biomedres.us/submit-manuscript.php
68. Mutchler SM, Straub AC (2015) Compartmentalized nitric oxide signaling in the resistance vasculature. Nitric Oxide 49: 8-15.

69. Tanaka LY, Bechara LRG, dos Santos AM, Jordao CP, de Sousal LG, et al. (2015) Exercise improves endothelial function: A local analysis of production of nitric oxide and reaction oxygen species. Nitric Oxide 45: 7-14.

70. Suh SH, Paik IY, Jacobs K (2007) Regulation of blood glucose homeostasis during prolonged exercise. Mol Cells 23: 272-279.

71. Neville CE, Young IS, Gilchrist SE, McKinley MC, Gibson A, et al. (2013) Effect of increased fruit and vegetable consumption on physical function and muscle strength in older adults. Age 35: 2409-2422.

72. Cesari M, Pahor M, Bartali B, Cherubini A, Penninx BW, et al. (2004) Antioxidants and physical performance in elderly persons: The invecciare in Chianti (InCHIANTI) study. Am J Clin Nutr 79: 289-294.

73. Halliwell B (2001) Vitamin C and genomic stability. Mutat Res 475: 2935.

74. McGoinley C, Shafat A, Donnelly AE (2009) Dose antioxidant vitamin supplementation protect against muscle damage? Sports Med 39: 10111032.

75. Dasgupta A, Klein K (2014) Antioxidants in food, vitamins and supplements: Prevention and treatment of disease. Academic Press, pp. 360.

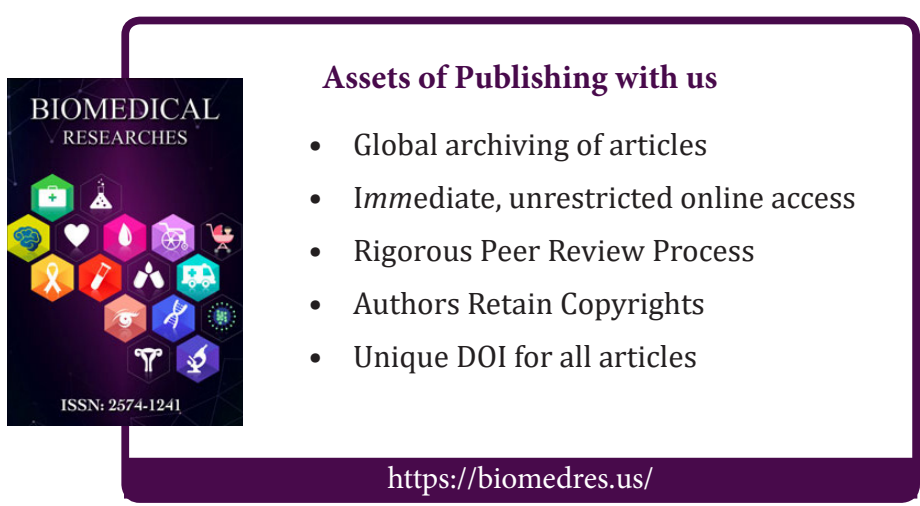

